\title{
Thermal monitoring of LiFePO4 batteries using switching harmonics
}

\author{
Cristina Gonzalez Moral, Daniel Fernandez, Juan Manuel Guerrero, David Reigosa and Fernando Briz \\ University of Oviedo. Dept. of Elect. Computer \& System Engineering, Gijón, 33204, Spain. \\ gmoralcristina@uniovi.es, fernandezalodaniel@uniovi.es, guerrero@uniovi.es, diazdavid@uniovi.es, \\ fernando@isa.uniovi.es
}

\begin{abstract}
Thermal monitoring is of high relevance for safe operation and degradation management of batteries. Direct measurement of battery temperature has drawbacks due both to cost and reliability issues. To overcome these limitations, development of temperature estimation methods has received significant research attention. Most of existing estimation methods are based in the injection of an additional signal, which can produce additional losses. This paper proposes a temperature estimation method for $\mathrm{LiFePO4}$ batteries using the switching harmonics of the converter feeding the battery. Temperature changes are estimated from the variation of the battery impedance at the switching frequency. The method operates online and without interfering with the normal operation of battery and power converter, and does not introduce therefore additional losses or any other adverse effect in the batteries. ${ }^{1}$
\end{abstract}

Index Terms - LFP batteries, thermal monitoring, temperature estimation, impedance estimation.

\section{Introduction}

The use of energy storage systems (ESS) based on batteries has dramatically increased during the last two decades. A wide variety of systems such as microgrids [1]-[3], electric vehicles (EV) [4]-[9] or aerospace applications [10]-[12] use batteries ESS, with energy/power requirements strongly depending on the application [12]. Development of battery monitoring methods aimed to guarantee safe operation and to improve their performance, reliability and lifetime being the focus of significant research efforts [3], [12]-[14].

Batteries can be classified as primary (not rechargeable) and secondary (rechargeable). Examples of primary batteries are zinc-carbon (Leclanché and zinc chloride), magnesium/manganese dioxide $\left(\mathrm{Mg} / \mathrm{MnO}_{2}\right)$ or alkalinemanganese dioxide (zinc $/ \mathrm{KOH} / \mathrm{MnO}_{2}$ ). Examples of secondary batteries are lead-acid, nickle-cadmium (NiCd), nickle-metal hydride (NiMH), lithium-ion (Li-ion) or Li-ion-polymer [15]. Lithium Ion Batteries (LIB) are the most common choice in high capacity ESS, which are very common in microgrids [1], [16], electric vehicles (EV) [5]-[7], [9] or satellites [12], [17], applications. Batteries are formed by three main elements: anode, cathode and electrolyte. Graphite is the most common anode choice in LIB batteries. LIB cathode materials are usually oxides, as lithium-cobalt oxide ( $\mathrm{LiCoO} 2$ or LCO), lithium- manganese oxides (LiMn2O4 or LMO) or lithium iron phosphate (LiFePO4 or LFP). Depending on the cathode, they can be classified in High Power (HP) or High Energy (HE) batteries [18]. Among LIB batteries, $\mathrm{LiFePO}_{4}$ are gaining popularity due to their advantages in terms of safety, low toxicity, long cycle life $(>2000)$, high power capability, reliability, relative low cost, wide temperature range $\left(-20^{\circ} \mathrm{C}-\right.$ $60^{\circ} \mathrm{C}$ ) and flat voltage profile. As a drawback, compared to other LIB batteries, they have low-average cell voltage (3.2V) and lower specific energy $(90-120 \mathrm{Wh} / \mathrm{kg})$ [5], [18], [19]. LIBs are very sensitive to temperature variations; e.g. Open Circuit Voltage (OCV), capacity or its internal resistance [9], [20]-[22] have been reported to be affected. Furthermore, operating temperature limits can be different during charging and discharging processes [23]. While higher battery temperature may temporarily increase its capacity, it also increases the internal resistance and therefore the losses, accelerates the aging and increases the risk of thermal runaways, fires and explosions [24]-[26]. Over $80^{\circ} \mathrm{C}$, thermal runaway can occur spontaneously due to the exothermic reactions taking place between electrolyte, anode and cathode [24]. This temperature may vary depending on the battery constructive elements, as the electrolyte solvents [25]. On the other hand, lower temperatures result in a reduction of the power and energy capabilities as the diffusion of the lithium in the electrolyte is reduced too [26], [27]. $\mathrm{A} \mathrm{LiFePO}_{4}$ battery as the one in [23] can operate between $-20^{\circ} \mathrm{C}$ and $60^{\circ} \mathrm{C}$ while discharging but only from $-10^{\circ} \mathrm{C}$ to $45^{\circ} \mathrm{C}$ while charging. It is concluded from the previous discussion that LIB temperature monitoring is of great importance, which explains the proliferation of temperature measurement [5], [9], [26] and estimation [25], [28]-[35] methods during the last decade.

LIB temperature can be directly measured using temperature sensors [32], as RTD (Resistance Temperature Detector) [29], like a PT100 [5], or thermocouples [26], [33]. While the sensors themselves can be cheap, their installation and the subsequent cabling, signal conditioning and acquisition, add cost and complexity, and can compromise the system reliability as there are more elements susceptible of failure. In addition, determining the number and location of the sensors to trade-off accuracy, cost and complexity is not trivial.

Alternatively, LIB temperature can be estimated [25], [28][35]. Estimation methods rely on relationship between the battery impedance and its temperature. The battery impedance

\footnotetext{
1 This work was supported in part by the Research, Technological Development and Innovation Programs of the Spanish Ministry Economy and Competitiveness, under grant MINECO-17-ENE2016-80047-R.
} 
is typically estimated by injecting sinusoidal currents, which are preferably injected when the battery is resting to improve the accuracy; however, this limits the applicability of the method.

This paper proposes temperature estimation for $\mathrm{LiFePO} 4$ batteries using the switching harmonics produced by the converter feeding the battery. Temperature is estimated from the measured battery impedance at the switching frequency. The proposed method avoids injection of additional signals and does not interfere with the normal operation of the battery. Sensitivity of the method to the State of Charge (SOC) will also be studied.

The paper is organized as follows: the electrical modeling of batteries is discussed in section III; the variation of battery voltage with SOC and the consequent need for a converter is studied in section IV; the proposed battery temperature estimation method using switching harmonics is presented in section V; experimental results are shown in section VI; conclusions are finally presented in section VII.

\section{Temperature estimation of LIB}

This section briefly reviews existing LIB temperature estimation methods. In [25], [28] phase shift between an applied sinusoidal current and the resulting voltage at $40 \mathrm{~Hz}$ was presented as a reliable metric on internal cell temperature. This method was further analyzed in [30], it was concluded that SOC affects low frequency impedances. Impedance measurement was performed at higher frequencies, i.e. $10.3 \mathrm{kHz}$, to avoid SOC influence. In [29] they also use the phase shift between voltage and current for temperature estimation, including SOC correction for a more precise estimation. In [31], the intercept frequency, which is the frequency in the Nyquist plot where the imaginary part is zero, was shown to be dependent solely on the cell temperature, not being affected by SOC and aging. In [32], a combination of impedance calculation based on voltage and current measurements and surface cell temperature measurements was presented to estimate the internal temperature in cylindrical $\mathrm{LiFePO}_{4}$ batteries. The battery is excited with a current at $215 \mathrm{~Hz}$ for this purpose, as this frequency was shown (see also [25] and [28]) to be high enough to be SOC independent. In [33] frequency selection to minimize the interference from SOC and $\mathrm{SOH}$ (State Of Health) for Liion batteries was analyzed. Depending on the temperature, the frequency range used to estimate the temperature without being influence by the SOC changes. The lowest frequency that can be used is almost independent of temperature, while the highest one changes significantly; specially challenging is the operation at low temperatures $\left(-10^{\circ} \mathrm{C}\right)$. This study also concludes that $\mathrm{SOH}$ has almost no effect on the phase angle of the battery impedance. The conclusion regarding frequencies selection for temperature estimation differ slightly from those in [32], a potential reason being the differences in LIB technologies used in each study. Finally, in [34], the method presented in [32] was improved by eliminating cell temperature measurements. Combined impedance measurements at $215 \mathrm{~Hz}$ and an extended Kalman filter (EKF) was used instead. Still the measurements must be made with the battery resting.

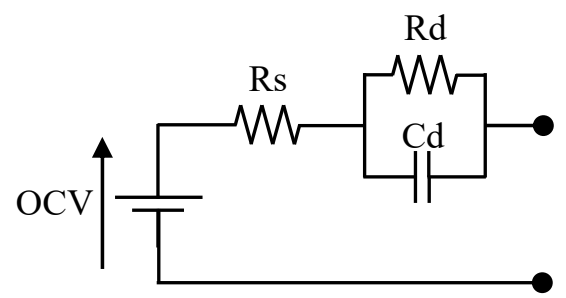

Fig. 1.- Thévenin equivalent model of a battery [6].

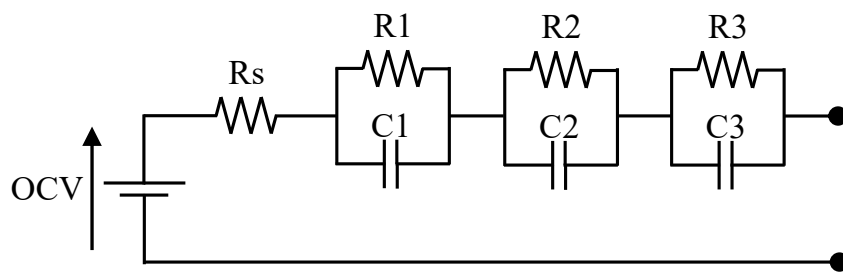

Fig. 2.- Battery model using a third order RC circuit.

\section{Electrical modeling of batteries}

Several electric equivalent-circuits have been proposed to model the electrical behavior of batteries, including Thévenin [6], [7], [41], RC [6], [37], [41] and Randles (impedance-based) [8], [10], [41] models. These models are a simpler, lower computational burden alternative to chemical and mathematical models [38], [39].

- Thévenin electric model: Consists of a voltage source in series with a resistor and a $\mathrm{RC}$ branch in parallel. It models the charging and discharging behavior of a battery with simple electric elements as shown in Fig. 1, where the voltage source represents the $\mathrm{OCV}, \mathrm{R}_{\mathrm{s}}$ accounts for the resistance of the contacts, electrodes and electrolyte while $R_{d}$ and $C_{d}$ accounts for the battery transient response. This model does not take into account parameter variation with aging or operating conditions.

- RC models: Consists of a voltage source in series with a resistor and several $\mathrm{RC}$ branches in parallel as shown in Fig. 2, where the voltage source is the $\mathrm{OCV}, \mathrm{R}_{\mathrm{s}}$ represents the internal resistance and the parallel branches (i.e. R1C1, R2C2, R3C3) model battery dynamics [41]. This model can be seen as an extension of the Thevenin model and does not take into account therefore parameter variation with time or operating conditions.

- Randles model: a widely extended methodology for battery characterization is the Electrochemical Impedance Spectroscopy (EIS). EIS-meters apply a sinusoidal AC voltage to the battery, the impedance being obtained from the applied voltage and the resulting current [33], [42]. Fig. 4a shows the EIS results for the batteries used in this paper (i.e. LiFePO4, see Fig. 3). The x-axis represents the real part of the impedance and the y-axis the imaginary part. Every point in the graph corresponds to a different frequency, the frequency increasing from right to left as shown in the figure. The impedance obtained by the EIS analysis is used to obtain the Randles model equivalent circuit (see Fig. 4b), where $R_{i}$ is the resistance of the 


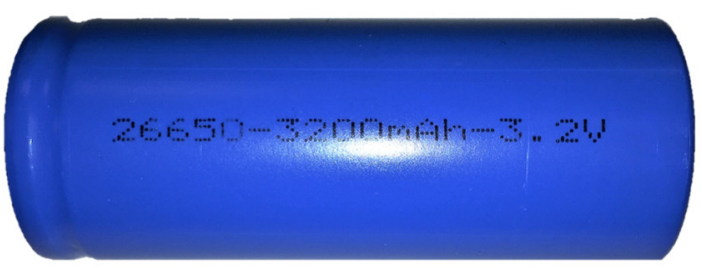

Fig. 3.- LiFePO4 battery.

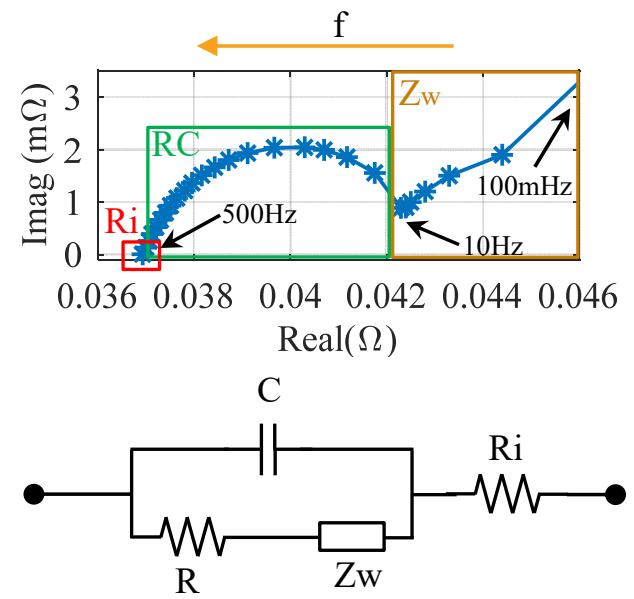

b)

Fig. 4.- a) EIS analysis. b) Randles equivalent model derived from the EIS analysis.

electrolyte and collector when the battery impedance changes from capacitive to inductive, $\mathrm{C}$ represents the double layer capacitance at the cathode/electrolyte and lithium/electrolyte interface, i.e. maximum reactance point in the semicircle (see Fig. 4), $\mathrm{R}$ is the charge transfer resistance (radius of the semicircle, see Fig. 4) and $Z_{W}$ represents the Warburg impedance which accounts for the diffusion phenomena [41]. Although its use is normally restricted to static analysis [33], EIS can also be used for transient impedance estimation, i.e. during battery charging/discharging [8].

In general, there is not a unique approximation to battery modeling, there are several possibilities involving combinations of simple electric elements. Among the aforementioned models, EIS is the most common choice for temperature estimation methods reported in the literature [25][35], and more specifically its resistive elements as they are expected to change linearly with the battery temperature. However, model parameters might also be affected by SOC and load, these issues being further discussed in section VI.

\section{Battery control using electronic power converter}

Voltage in a battery varies with SOC, voltage vs. SOC ratio depending on the type of battery [15]. $\mathrm{LiFePO}_{4}$ batteries have a rather flat behavior for medium SOCs, but variation from full (100\%) SOC to $0 \%$ SOC goes from $3.5 \mathrm{~V}$ to $2.6 \mathrm{~V}$ in a single cell (see Fig. 5); $\mathrm{LiFePO}_{4}$ batteries being used usually between $20 \%$ and $80 \%$ SOC, because in this region the curve is more flat, but not completely constant. A solution to overcome the issue of the battery voltage dependency with SOC is adding a

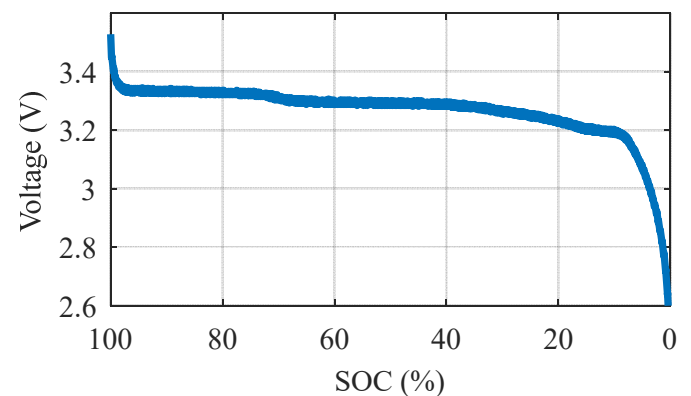

Fig. 5.- SOC curve of a $\mathrm{LiFePO}_{4}$ cell (discharge).

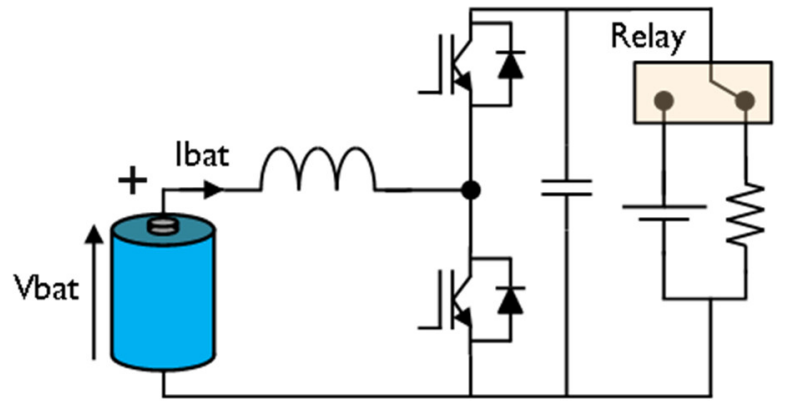

Fig. 6.- Boost converter scheme used to charge and discharge the battery.

$\mathrm{DC} / \mathrm{DC}$ converter in between the batteries and the rest of the system to stabilize the DC voltage independently of battery SOC, with the drawback of the cost of the converter [2], [4]. In some systems where the DC voltage must be very stable, or cases in which the output voltage is so high that using a high number or series connected cells is not practical, this converter is unavoidable [4]. These converters can also provide galvanic isolation if required. Examples of converters used for battery integration are NPC converters, without isolation (for direct coupling), or Dual Active Bridge (DAB), with isolation thanks to the high frequency transformer. They can be found in microgrids or electric vehicles, among others [2], [4]. In any of these cases, the converter will generate harmonics, which will affect the voltage and current waveform in the battery. In this paper, the bidirectional boost converter shown in Fig. 6 will be used. Table I show the most important parameters of the set-up. Current control block diagram is shown in Fig. 7, where $\mathrm{I}_{\mathrm{L}} *$ is the current command, $\mathrm{I}_{\mathrm{bat}}$ is the battery current, $\mathrm{e}_{\mathrm{i}}$ is the current error, $\mathrm{V}_{\text {bat }}$ is the battery voltage. $\mathrm{V}_{\text {out }}$ is the power converter output current, $\mathrm{V}_{\mathrm{L}}$ is the inductor current, $\mathrm{d}$ is the power converter duty cycle and $\mathrm{G}(\mathrm{s})$ represents the plant, i.e, the battery. A PI is used to control the battery current.

TABLE I

BIDIRECTIONAL BOOST CONVERTER AND BATTERY CHARACTERISTIC PARAMETERS.

\begin{tabular}{|l|c|}
\hline \multicolumn{1}{|c|}{ Parameter } & Value \\
\hline Switching frequency & $15 \mathrm{kHz}$ \\
\hline Converter inductor & $478 \mu \mathrm{H}$ \\
\hline Nominal battery voltage & $3.2 \mathrm{~V}$ \\
\hline Nominal current & $3.2 \mathrm{~A}$ \\
\hline Maximum charge current & $1 \mathrm{C}$ \\
\hline Maximum discharge current & $3 \mathrm{C}$ \\
\hline Battery capacity & $3300 \mathrm{mAh}$ \\
\hline MOSFETs nominal voltage & $75 \mathrm{~V}$ \\
\hline MOSFETs nominal current & $56 \mathrm{~A}$ \\
\hline
\end{tabular}




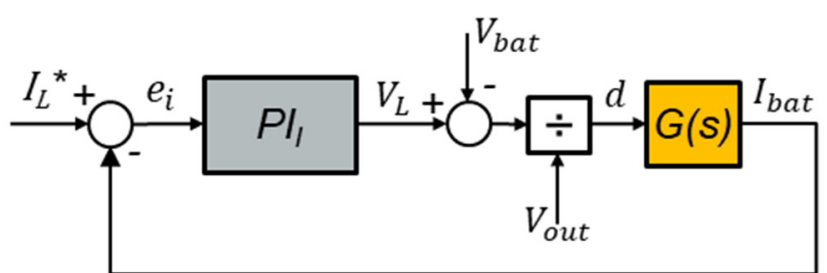

Fig. 7.-Battery current controller.

\section{Battery temperature estimation using switching harmonics}

This section presents the proposed battery temperature estimation method using switching harmonics. Fig. 8 and Fig. 9 show an example of the wave shapes and corresponding frequency spectrums of the current and voltage when the current in the battery is controlled to be $1.7 \mathrm{~A}$ (discharging current). In addition to the DC component, harmonics at integer multiples of the switching frequency are readily visible in the frequency spectrum. Battery current and voltage can be expressed as (1) and (2) respectively, where $\mathrm{I}_{\mathrm{DC}}$ and $\mathrm{V}_{\mathrm{DC}}$ are the DC components, $I_{n}$ and $V_{n}$ are the magnitudes of the $n^{\text {th }}$ harmonic components of the current and voltage respectively, $f_{\text {sw }}$ is the switching frequency and $\varphi_{\mathrm{Vn}}$ and $\varphi_{\text {In }}$ are the angles of the voltage and current $\mathrm{n}^{\text {th }}$ harmonic component respectively. The battery impedance can be obtained from any of the harmonic components of the voltage and current (3), where $\mathrm{R}_{\text {batn }}$ and $\mathrm{X}_{\text {batn }}$ are the battery resistance and reactance at the frequency of the $\mathrm{n}^{\text {th }}$ harmonic component. The battery resistance is modeled as to be a linear function of the battery temperature (4), the battery temperature, (5), can be therefore easily obtained from (3)-(4).

$$
\begin{aligned}
& I_{\text {bat }}=I_{D C}+\sum_{n} I_{n} \sin \left(n \cdot 2 \pi f_{s w} t+\varphi_{I n}\right) \\
& V_{b a t}=V_{D C}+\sum_{n} V_{n} \sin \left(n \cdot 2 \pi f_{s w} t+\varphi_{V n}\right) \\
& Z_{n}=\frac{V_{n} \sin \left(n \cdot 2 \pi f_{s w} t+\varphi_{V n}\right)}{I_{n} \sin \left(n \cdot 2 \pi f_{s w} t+\varphi_{I n}\right)}= \\
& =\frac{V_{n}}{I_{n}}\left[\cos \left(\varphi_{V n}-\varphi_{I n}\right)+j \sin \left(\varphi_{V n}-\varphi_{I n}\right)\right]=R_{\text {batn }}+j X_{\text {batn }} \\
& R_{\text {batn }}=R_{\text {batn } 0}\left(1+\alpha_{\text {bat }}\left(T_{\text {bat }}-T_{0}\right)\right) \\
& T_{\text {bat }}=\frac{R_{\text {batn }}-R_{\text {batn0 }}}{R_{\text {batno }} \alpha_{\text {bat }}}+T_{0}
\end{aligned}
$$

The signal processing for temperature estimation is shown in Fig. 10. The inputs are the battery current and voltage, which both contain the DC fundamental component and the switching harmonics. Two Band Pass Filters (BPF) are used to isolate the harmonic component at the switching frequency of each signal; battery high frequency impedance $\left(Z_{\text {batn }}\right)$ being obtained from (3). The battery high frequency resistance $\left(\mathrm{R}_{\text {batn }}\right)$ is obtained as the real part of the resulting impedance and the estimated battery temperature $\left(\mathrm{T}^{*}\right)$ is obtained from (5).
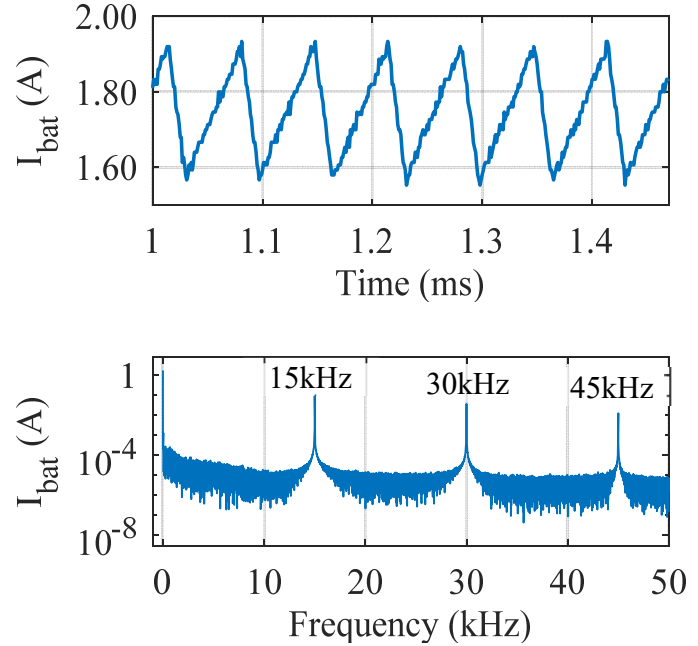

b)

Fig. 8.- a) Battery current, Ibat , and b) FFT of Ibat. Battery discharging (a) $20^{\circ} \mathrm{C}$.

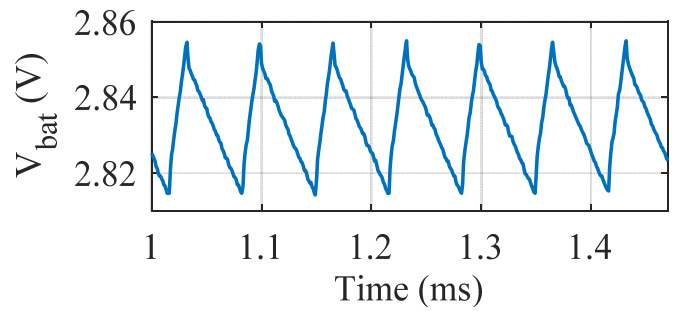

b)

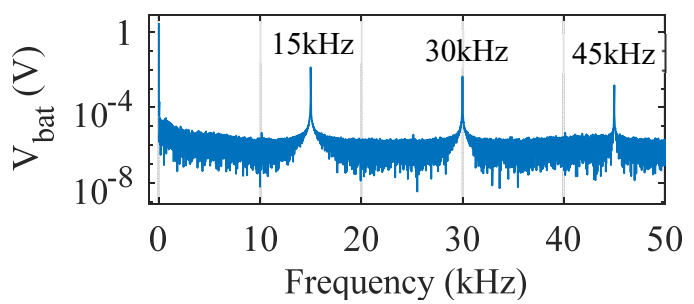

Fig. 9.- a) Battery voltage, $V_{b a t}$, and b) FFT of $V_{b a t}$. Battery discharging (a) $20^{\circ} \mathrm{C}$.

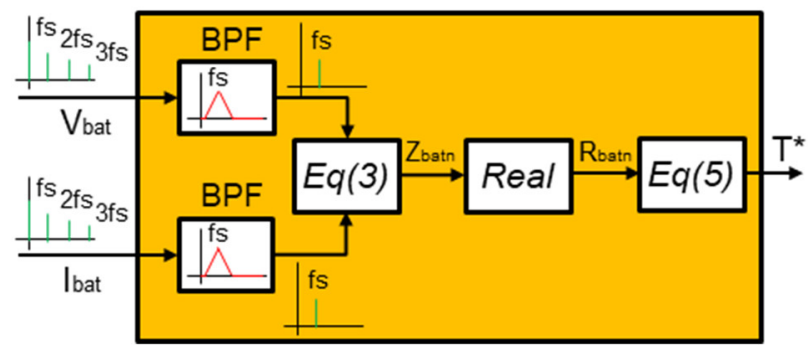

Fig. 10.-Signal processing for battery temperature estimation.

\section{Experimental results}

Fig. 11 shows a picture of the power converter in Fig. 6. Battery voltages and currents are measured using a 16 bits data acquisition system. $\mathrm{LiFePO}_{4}$ batteries used in the experiments are $3.2 \mathrm{~V}, 3300 \mathrm{mAh}$ with $1 \mathrm{C}$ and $3 \mathrm{C}$ of maximum charging and discharging current respectively (see Fig. 3). The converter uses IRFU3607 MOSFETs [43] (Table I). 


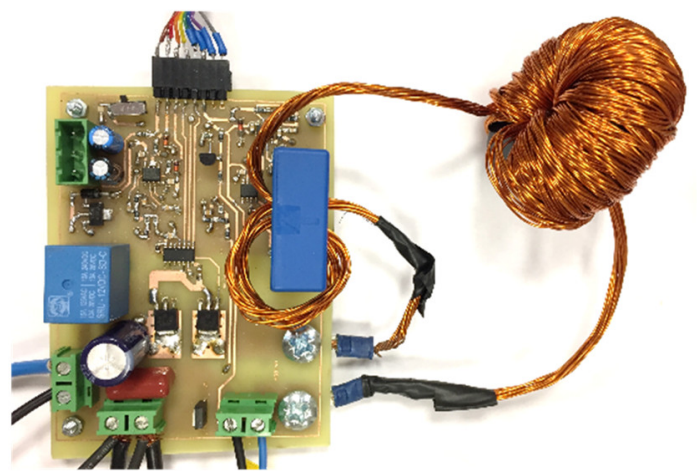

Fig. 11.- Power converter prototype.

\section{VI.A. Resistance variation with $\mathrm{SOC}$}

Fig. 12a and Fig. 12b shows the battery resistance vs. discharging DC current at the switching frequency for different SOCs and for two different $\mathrm{LiFePO}_{4}$ batteries respectively. Battery internal resistance is shown to vary less than $1.7 \%$ when the discharging current changes from $0.6 \mathrm{~A}(0.15 \mathrm{C})$ to $5.6 \mathrm{~A}$ $(1.75 \mathrm{C})$. The variation rate of the battery internal resistance with the discharging current is $\approx 0.08 \mathrm{~m} \Omega / \mathrm{A}$, and almost independent of the SOC. Fig. 13 shows the variation of the

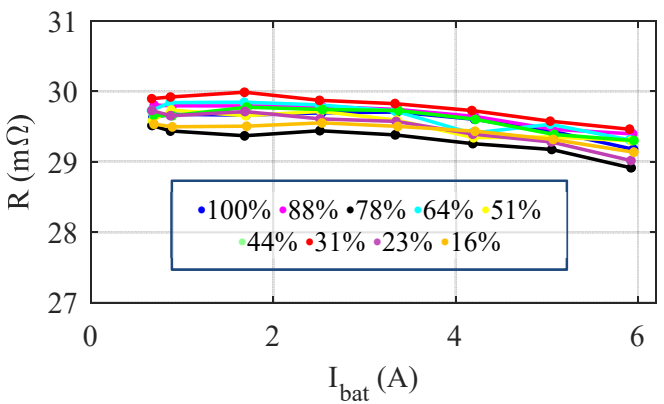

a)

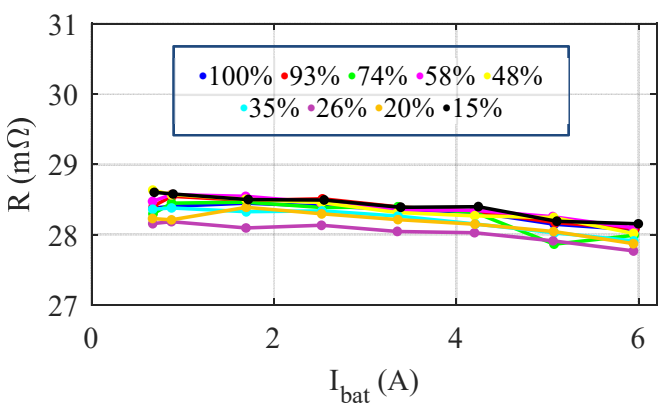

b)

Fig. 12.- Battery resistance (@ $15 \mathrm{kHz}$ ) vs. discharging DC current for different SOCs for battery B1 (a) and B2 (b). $\mathrm{T}=22^{\circ} \mathrm{C}$.

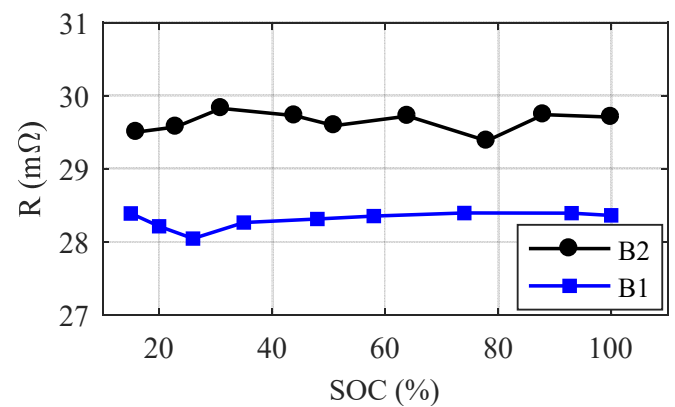

Fig. 13.- Variation of $\mathrm{R} @ 15 \mathrm{kHz}$ at $3.2 \mathrm{~A}$ discharge current with $\mathrm{SOC}$ for the two batteries in Fig. 12.
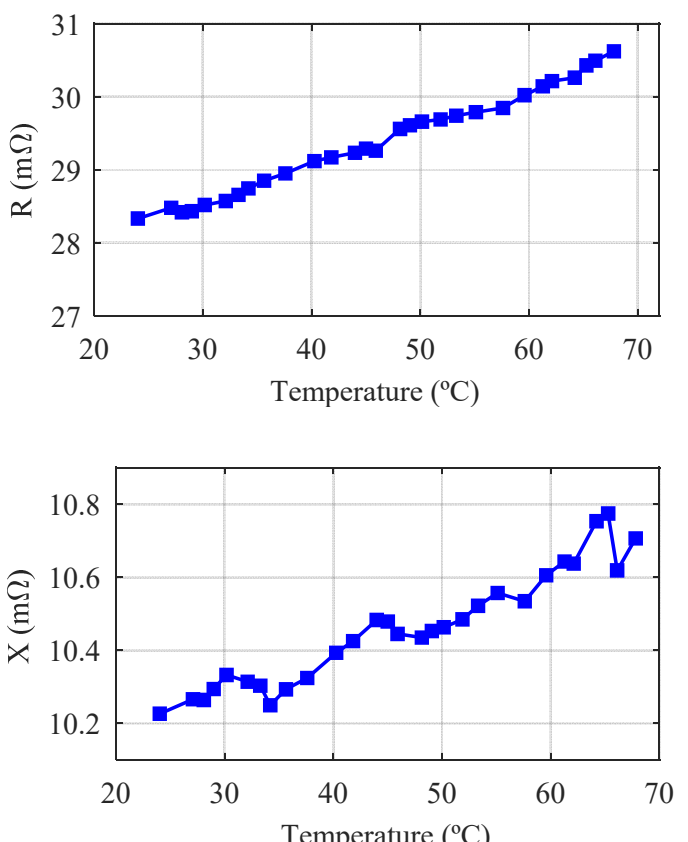

Temperature $\left({ }^{\circ} \mathrm{C}\right)$

Fig. 14.- Battery resistance, a), and reactance, b), @15 kHz vs. battery temperature. $\mathrm{I}_{\mathrm{DC}}=3.2 \mathrm{~A}$.

battery internal resistance with the $\mathrm{SOC}$ at $1 \mathrm{C}$ discharging rate. It is observed that the battery internal resistance is almost independent of the SOC.

\section{VI.B. Resistance and reactance variation with temperature}

Fig. 14a and Fig. 14b show the battery resistance and reactance at the switching frequency vs. the battery temperature for cell B1 in Fig. 12. Battery was initially heated up to $\approx 70^{\circ} \mathrm{C}$, the battery impedance being measured while the battery freely cools down with no DC current. Resistance is seen to change almost linearly with temperature, while reactance trend is not so evident. It is also observed from Fig. 12 and Fig. 14 that resistance variations with SOC and discharging DC current are negligible compared to variations due to temperature [30], [32], [33], meaning that SOC and DC fundamental current are not expected to impact the reliability of the proposed method significantly. These results confirm therefore the validity of the proposed method for battery temperature estimation.

The experimental results shown in Fig. 14a have been performed in four additional $\mathrm{LiFePO}_{4}$ units, the results being shown in Fig. 15. It is observed that there is an offset in the internal resistance among cells, however the rate of variation of the internal battery resistance is almost the same for all batteries. Since the battery temperature will be estimated from the variation of the resistance with temperature respect to their resistance at the room temperature, offsets among cells are not expected to affect to the accuracy of the method. Fig. 16 shows the measured and estimated temperature using (5); $\alpha_{\text {bat }}$ $\left(\approx 0.0617 \mathrm{~m} \Omega /{ }^{\circ} \mathrm{C}\right)$ being obtained as the average of $\alpha_{\text {bat }}$ for the four cells that have been analyzed (see Fig. 15). 


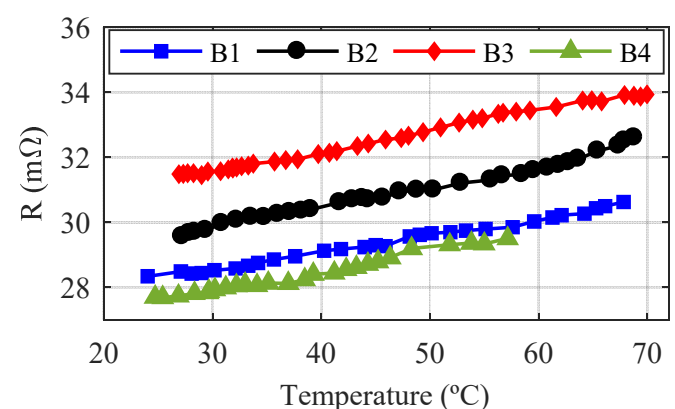

Fig. 15.- Battery resistance (@15 kHz) vs. battery temperature for different batteries. $\mathrm{I}_{\mathrm{DC}}=3.2 \mathrm{~A}$.
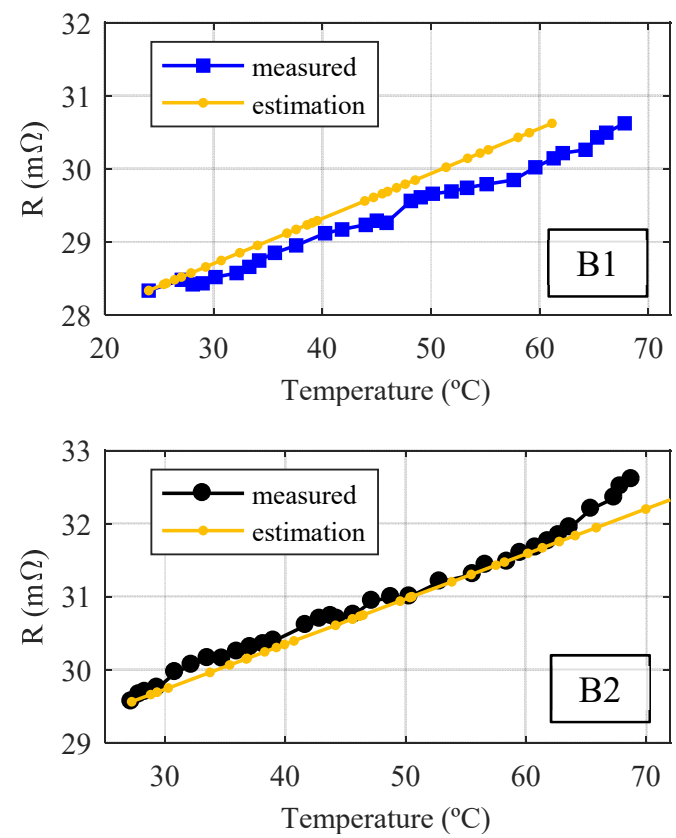

b)

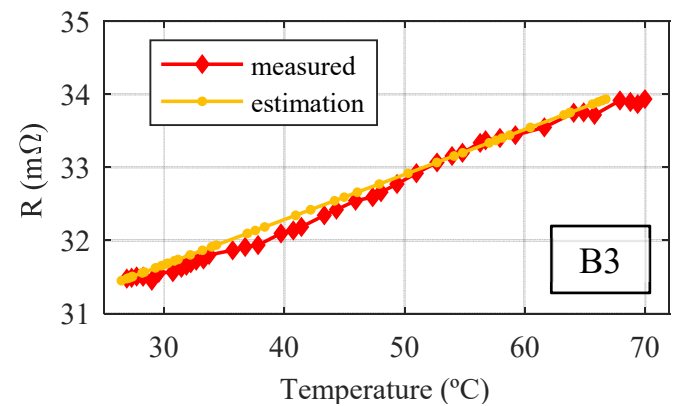

c)

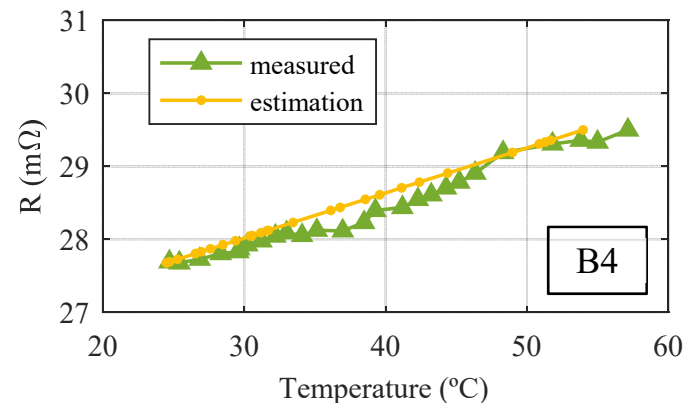

d)

Fig. 16.- Measured and estimated temperatures for four different batteries, B1-B4. fsw $=15 \mathrm{kHz}$. IDC $=3.2 \mathrm{~A}$.

Fig. 17 shows the temperature estimation error for all batteries analyzed in Fig. 16; the temperature estimation error is seen to be less than $\approx 9^{\circ} \mathrm{C}$.

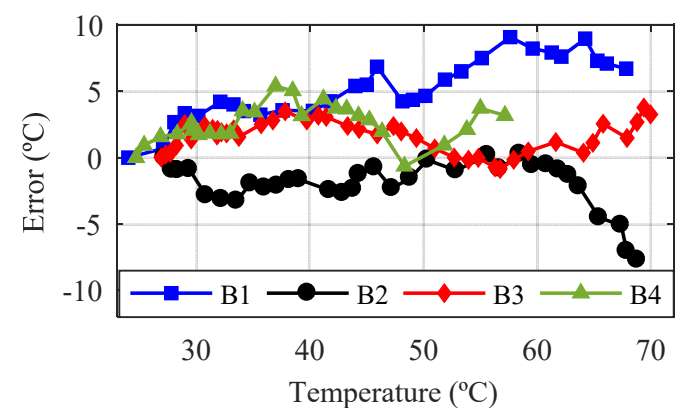

Fig. 17.- Error between measured and estimated temperature. fsw $=15 \mathrm{kHz}$, $\mathrm{IDC}=3.2 \mathrm{~A}$.

\section{Conclusions}

This paper proposes a temperature estimation method for LiFePO4 batteries using switching harmonics produced by the power converter used to feed the battery. Temperature is estimated from the measured battery resistance at the switching frequency. The method allows online temperature monitoring without injecting additional signals and without interfering with the normal operation of the system. It has been shown that the SOC and the discharging DC current almost do not affect the method reliability. Experimental results have been provided to demonstrate the viability of the proposed method.

\section{References}

[1] I. Alsaidan, W. Gao and A. Khodaei, "Optimal design of battery energy storage in stand-alone brownfield microgrids," North American Power Symposium (NAPS), Morgantown, WV, pp. 1-6, Sept. 2017.

[2] Z. Miao, L. Xu, V. R. Disfani and L. Fan, "An SOC-Based Battery Management System for Microgrids," IEEE Transactions on Smart Grid, vol. 5, no. 2, pp. 966-973, March 2014.

[3] M. T. Lawder, B. Suthar, P. W. C. Northrop, S. De, C. M. Hoff, O. Leitermann, M. L. Crow, S. Santhanagopalan, V. R. Subramanian, "Battery Energy Storage System (BESS) and Battery Management System (BMS) for Grid-Scale Applications," Proceedings of the IEEE, vol. 102, no. 6, pp. 1014-1030, June 2014.

[4] M. Bragard, N. Soltau, S. Thomas and R. W. De Doncker, "The Balance of Renewable Sources and User Demands in Grids: Power Electronics for Modular Battery Energy Storage Systems," IEEE Transactions on Power Electronics, vol. 25, no. 12, pp. 3049-3056, Dec. 2010.

[5] D. Anseán, M. González, V. M. García, J. C. Viera, J. C. Antón and C. Blanco, "Evaluation of $\mathrm{LiFePO}_{4}$ Batteries for Electric Vehicle Applications," IEEE Transaction on Industrial Application, vol. 51, no. 2, pp. 1855-1863, March-Apr 2015.

[6] M. Einhorn, F. V. Conte, C. Kral and J. Fleig, "Comparison, Selection, and Parameterization of Electrical Battery Models for Automotive Applications," IEEE Transactions on Power Electronics, vol. 28, no. 3, pp. 1429-1437, March 2013.

[7] M. Einhorn, V. F. Conte, C. Kral, J. Fleig and R. Permann, "Parameterization of an electrical battery model for dynamic system simulation in electric vehicles," IEEE Vehicle Power and Propulsion Conference, Lille, pp. 1-7, Sept. 2010.

[8] S. Buller, M. Thele, E. Karden, R. W. D. Doncker, "Impedance-based non-linear dynamic battery modeling for automotive applications," Journal of Power Sources, vol. 113, no. 2, pp. 422-430, Jan. 2003

[9] A. E. Mejdoubi, H. Gualous, H. Chaoui and G. Alcicek, "Experimental investigation of calendar aging of lithium-ion batteries for vehicular applications," EMC Conference, Turkiye, Ankara, pp. 1-5, Sept. 2017.

[10] M. Sayegh, C. Forgez, T. H. Tran and G. Cherouvrier, "LiFePO4/graphite battery modelling for an aeronautical application," IEEE-ISIE, Buzios, pp. 1278-1283, June 2015.

[11] J.P. Fellner, G.J. Loeber, S.P. Vukson, C.A. Riepenhoff, "Lithium-ion testing for spacecraft applications," Journal of Power Sources, vol. 119121, pp. 911-913, 2003 
[12] Gianfranco Pistoia, "In Battery Operated Devices and Systems," Elsevier, Amsterdam, 2009.

[13] H. Rahimi-Eichi, U. Ojha, F. Baronti and M. Y. Chow, "Battery Management System: An Overview of Its Application in the Smart Grid and Electric Vehicles," IEEE Industrial Electronics Magazine, vol. 7, no. 2, pp. 4-16, June 2013.

[14] J. Cao, N. Schofield and A. Emadi, "Battery balancing methods: A comprehensive review," IEEE Vehicle Power and Propulsion Conference, Harbin, pp. 1-6, Sept. 2008.

[15] D. Linden and T. Reddy, "Handbook of Batteries," Edición: 3. New York: McGraw-Hill Professional, 2001.

[16] B. Weißhar and W. G. Bessler, "Model-based degradation assessment of lithium-ion batteries in a smart microgrid," International Conference on Smart Grid and Clean Energy Technologies (ICSGCE), Offenburg, pp. 134-138, Oct. 2015.

[17] J. C. Koo, S. K. Lee and S. W. Ra, "Lithium-ion battery design for the hybrid satellite in the geostationary orbit," International Telecommunications Energy Conference (INTELEC), Incheon, pp. 1-6, Dec. 2009

[18] D. A. González, "High power Li-ION battery performance: A mechanistic analysis of aging." $\mathrm{PhD}$ thesis, University of Oviedo, 2015. Available: http://hdl.handle.net/10651/34551 [Accessed: Jan 16, 2018].

[19] AA Portable Power Corp, "LiFePO4/LiFeMnPO4 Batteries". Available: https://www.batteryspace.com/LiFePO4/LiFeMnPO4-Batteries.aspx [Accessed: Jan 16, 2018].

[20] F. Feng, R. Lu, G. Wei and C. Zhu, "Identification and analysis of model parameters used for $\mathrm{LiFePO} 4$ cells series battery pack at various ambient temperature," IET Electrical Systems in Transportation, vol. 6, no. 2, pp. 50-55, May 2016.

[21] M. Takahashi, S. Tobishima, K. Takei, Y. Sakurai, "Reaction behavior of $\mathrm{LiFePO}_{4}$ as a cathode material for rechargeable lithium batteries," Solid State Ionics, vol. 148, no. 3-4, pp. 283-289, June 2002.

[22] L. W. Juang, P. J. Kollmeyer, T. M. Jahns and R. D. Lorenz, "Improved modeling of lithium-based batteries using temperature-dependent resistance and overpotential," IEEE-ITEC, Dearborn, MI, pp. 1-8, June 2014.

[23] ENIX Energies, "Specification Approval Sheet," ACL9012 -3.3Ah datasheet. Document number S470XLB029. Apr 2012. Version A0.

[24] Q. Wang, P. Ping, X. Zhao, G. Chu, J. Sun, C. Chen, "Thermal runaway caused fire and explosion of lithium ion battery," Journal of Power Sources, vol. 208, pp. 210-224, June 2012.

[25] R. Srinivasan, B. G. Carkhuff, M. H. Butler, A. C. Baisden, "Instantaneous measurement of the internal temperature in lithium-ion rechargeable cells," Electrochimica Acta, vol. 56, no. 17, pp. 6198-6204, July 2011.

[26] C. Alaoui, "Solid-State Thermal Management for Lithium-Ion EV Batteries," IEEE Transactions on Vehicular Technology, vol. 62, no. 1, pp. 98-107, Jan. 2013.

[27] K. Zaghib, K. Striebel, A. Guerfi, J. Shim, M. Armand, M Gauthier, "LiFePO4/polymer/natural graphite: low cost Li-ion batteries," Electrochimica Acta, vol. 50, pp. 263-270, Nov 2004.

[28] R. Srinivasan, "Monitoring dynamic thermal behavior of the carbon anode in a lithium-ion cell using a four-probe technique," Journal of Power Sources, vol. 198, pp. 351-358, Jan. 2012.

[29] R. Schwarz, K. Semmler, M. Wenger, V. R. H. Lorentz and M. März, "Sensorless battery cell temperature estimation circuit for enhanced safety in battery systems," Annual Conference of the IEEE Industrial Electronics Society (IECON), Yokohama, pp. 001536-001541, Nov. 2015.

[30] J. P. Schmidt, S. Arnold, A. Loges, D. Werner, T. Wetzel, E. Ivers-Tiffée, "Measurement of the internal cell temperature via impedance: Evaluation and application of a new method," Journal of Power Sources, vol. 243, pp. 110-117, Dec. 2013.

[31] L.H.J. Raijmakers, D.L. Danilov, J.P.M. van Lammeren, M.J.G. Lammers and P.H.L. Notten, "Sensorless battery temperature measurements based on electrochemical impedance spectroscopy," Journal of Power Sources, vol. 247, pp. 539-544, Feb. 2014

[32] R. R. Richardson, P. T. Ireland, D. A. Howey, "Battery internal temperature estimation by combined impedance and surface temperature measurement," Journal of Power Sources, vol. 265, pp. 254-261, Nov. 2014.

[33] J.G. Zhu, Z.C. Sun, X.Z. Wei, H.F. Dai, "A new lithium-ion battery internal temperature on-line estimate method based on electrochemical impedance spectroscopy measurement," Journal of Power Sources, vol. 274, pp. 990-1004, Jan. 2015.

[34] R. R. Richardson and D. A. Howey, "Sensorless Battery Internal Temperature Estimation Using a Kalman Filter With Impedance
Measurement," IEEE Transactions on Sustainable Energy, vol. 6, no. 4, pp. 1190-1199, Oct. 2015.

[35] L. H. J. Raijmakers, D. L. Danilov, J. P. M. V. Lammeren, T. J. G. Lammers, H. J. Bergveld and P. H. L. Notten, "Non-Zero Intercept Frequency: An Accurate Method to Determine the Integral Temperature of Li-Ion Batteries," IEEE Transactions on Industrial Electronics, vol. 63, no. 5, pp. 3168-3178, May 2016

[36] H. Rahimi-Eichi and M. Y. Chow, "Adaptive parameter identification and State-of-Charge estimation of lithium-ion batteries," IECON 2012 - 38th Annual Conference on IEEE Industrial Electronics Society, Montreal, QC, pp. 4012-4017, oct 2012.

[37] C. Birkl and D. Howey, "Model identification and parameter estimation for LiFePO4 batteries," IET Hybrid and Electric Vehicles Conference (HEVC), London, pp. 1-6, Nov. 2013.

[38] J. Newman, K. E. Thomas, H. Hafezi and D. R. Wheeler, "Modeling of lithium-ion batteries," Journal of Power Sources, vol. 119-121, pp. 838843, June 2003.

[39] L. Gagneur, A.L. Driemeyer-Franco, C. Forgez, G. Friedrich, "Modeling of the diffusion phenomenon in a lithium-ion cell using frequency or time domain identification," Microelectronics Reliability, vol. 53, no. 6, pp. 784-796, June 2013.

[40] M. K. Hossain, S. M. R. Islam and S. Y. Park, "Battery impedance measurement using sinusoidal ripple current emulator," IEEE Energy Conversion Congress and Exposition (ECCE), Cincinnati, OH, pp. 27542750, Oct. 2017.

[41] R. Ahmed, "Modeling and state of charge estimation of electric vehicle batteries." PhD thesis, McMaster University, 2014.

[42] Digatron Power Electronics, "Electrochemical Impedance Spectroscopy EIS-Meter". Available: http://www.digatron.com/en/cells-packs/ [Accessed: Jan 17, 2018].

[43] Infineon, IRFR3607PbF datasheet, Apr, 2010. 